\title{
EVALUATION OF INDIGENOUS FUNGAL ISOLATES AND METARHIZIUM ANISOPLIAE VAR. ACRIIDUM AGAINST ADULT LESSER WAX MOTH, ACHROIA GRISELLA (L) (PYRALIDAE: LEPIDOPTERA)
}

\author{
Emiru Seyoum and H. Namusana \\ ${ }^{1}$ Department of Biology, Faculty of Science, Addis Ababa University, PO Box 1176 \\ Addis Ababa, Ethiopia. E-mail: esyeshanew@yahoo.com
}

\begin{abstract}
The lesser wax moth (LWM) is a widely distributed and devastating insect pest to the honey production sector in Ethiopia. The present study aimed at investigating the potential of native fungal isolates against the lesser wax moth and assessing non target effect of one isolate of Beauveria (IITA 18) and five isolates of Metarhizium (IMI 330189, DLCO-AA83, DLCO-AA 109, DLCO-AA5, DLCO-AA14) via inoculating Ethiopian honeybee race, Apis mellifera bandasii. The effects of these six fungal isolates were evaluated in the laboratory for their pathogenicity to adult lesser wax moths. Spore dilutions were prepared in $0.5 \%$ Tween 80 . Adults were treated by spraying $2 \mathrm{ml}$ of conidial suspensions ranging from $2 \times 10^{4}$ to $2 \times 10^{7}$ conidia/ml. Adult lesser wax moths were found to be susceptible to all isolates and concentrations used. Comparison of post-treatment mortality of adult, lesser wax moth (LWM) at the lowest concentration $\left(2 \times 10^{4}\right.$ conidia/ml) revealed that infection of $\geq$ $90 \%$ could be achieved by day 8 post inoculation. Investigation into effects of mycosis on percentage emergence of adults from fungal treated last instar larvae of the LWM showed no significant difference $(\mathrm{P}>0.05)$ between the treated and untreated controls. Laboratory based experiments on the host specificity of the six fugal isolates had no effect in which only 1 individual honeybee $(0.5 \%)$ was infected with isolate IITA 18 (Beauveria spp.) while isolate DLCO-AA83 (Metarhizium spp.), caused infection in 2 individual honeybees.
\end{abstract}

Key words/phrases: Beauveria, honeybee, lesser wax moth, metarhizium, pathogenicity

\section{INTRODUCTION}

Lesser wax moth (LWM) (Pyralidae: Lepidoptera) is a serious pest in beehives and can cause substantial losses of combs, damage to beehive material and spoil beehive products. It is a widely distributed and devastating insect pest to honey production in Ethiopia through unabated damage to honeybees (Desalegn Begna, 2001; Desalegn Begna and Amsalu Bezabeh, 2001). The larval stage of the LWM feeds on the honey, pollen, and wax produced by honeybees. The damage is manifested in such a way that they eat and destroy beeswax combs, form silken feeding tunnels, bore through honey wax caps and cement the cocoon in cavities of beehive frames. Severe infestation by larvae often leads to comb collapse (Desalegn Begna, 2001).

On the other hand, Floyd and Paul (1976) reported that adult LWM affect honeybees indirectly as vectors of honeybee diseases, the worst of which is the foulbrood, an invasive mycosis produced by the fungus Ascosphaera apis, affecting stretched larvae. Various control meas- ures had been practiced against the lesser wax moth. It has been well documented that different isolates of the entomopathogenic fungi, Metarhizium and Beauveria have proved to be potential candidates for many insect pests (Burge, 1988). This study investigated the potential of two local isolates in comparison with one isolate taken as a standard isolate, Metarhizium anisopliae var. acridium (IMI 330189) in comparison with recently explored five local isolates against adult wax moths (Emiru Seyoum and Merid Negash, 2007; Namusana and Emiru Seyoum, 2010). The possible effect of the fungal isolates on the honeybee colonies (as non-target organisms) was also investigated (Namusana and Emiru Seyoum, 2010). However, an effective control method of this pest has not been developed. Physical, chemical, and biolog-ical methods are imperfect (Cantwell and Smith, 1970; Ali et al., 1973; Burges, 1978), and further studies are needed to find more effective control methods. Therefore, this study is intended to evaluate the potential effects of different fungal isolates as possible LWM control options. 


\section{MATERIALS AND METHODS}

The materials and methods deployed in this study were similar to a previous work on greater wax moth (Namusana and Emiru Seyoum, 2010) and those on grasshoppers (Emiru Seyoum and Merid Negash, 2007).

\section{Sources of experimental insects (LWM, honeybees) and fungal isolates}

The initial stock culture of the target lesser wax moth and wax combs for rearing of honeybees were obtained from Holleta Bee Research Centre, and reared at the insect rearing facilities of the Department of Biology, Addis Ababa University (AAU) and that of the Desert Locust Control Organization for Eastern Africa (D.L.C.O-E.A), Addis Ababa, Ethiopia. The lesser wax moths were fed with honeybee wax combs and artificial diet prepared using methods described by previous workers (Good et al., 1953; Haydak, 1976). Wax combs were put into the old culture for females to lay eggs for it contains a component of the female sex hormone Nonanal (MAAREC, 2000). All the experiments were carried out at AAU and D.L.C.O-E.A research facilities in 2004.

A total of 10 newly emerged adult female and 5 males LWM were introduced into new rearing containers with artificial diet and wax comb for rearing. Identifications of female and male were done using keys (Donald et al., 1989; Mike et al., 2002) and museum specimens at the Natural Zoological History Museum of Addis Ababa University. The containers were then placed in a warm room with temperature set at $30 \pm 2^{\circ} \mathrm{C}$. Humidity in the rearing room was maintained at $85 \%$ by spraying $500 \mathrm{ml}$ of water using a screw nozzle sprayer daily. A soft cardboard was placed in the rearing containers for pupation of fully-grown larvae. Soon after emergence, the immature adults LWM were transferred to a new rearing container so that same age LWMs were used for the subsequent experiments. On the other hand, four viable active Ethiopian races of Apis mellifera bandasii (Amsalu Bezabih et al., 2004) honeybee colonies were purchased from farmers in Bishoftu about $45 \mathrm{Km}$ south-east of Addis Ababa and were confined in wooden box hives. The colonies were fed with pure honey and $30 \%$ sugar solutions and received similar management practices.

The entomopthogenic fungal isolates of Beauveria (DLCO-AA5, DLCO-AA14 and IITA 18) and of Metarhizium (DLCO-AA 109 and DLCOAA83) were obtained from the stocks of DLCO collections in Ethiopia whereas the standard isolate, IMI 330189 was obtained from BCP Ltd. (a South African Company that produces the pathogen at commercial scale) (Table 1).

The pathogens were cultured on Sabouraud Dextrose Agar (SDA) plates. Antibiotic solution of Chloramphenicol was added to the sterilized agar medium. Isolates were cultured at a $\mathrm{pH}$ of 6.8 and $25^{\circ} \mathrm{C}$ for $10-14$ days to achieve maximum growth and sporulation (Seneshaw Aysheshim et al., 2003). Conidia were harvested by flooding 10 $\mathrm{ml}$ of sterile distilled water containing 0.5\% Tween 80 on agar plates. Conidial suspensions were adjusted to $2 \times 10^{4}-2 \times 10^{7}$ conidia $/ \mathrm{ml}$. Conidial concentrations were determined using a phase contrast light microscope and a stage haemocytometer (Prior et al., 1992).

Spore viability tests were carried out routinely through out the experiments by pipetting $200 \mu \mathrm{l}$ of spore formulation onto a $9 \mathrm{~cm}$ glass petri dish with SDA and viability was determined based on percentage germination (Hall, 1976; Emiru Seyoum, 2001). Spore batches with $>85 \%$ germination were considered to be viable and used.

Table 1. Fungal isolates used, source substrates, and country of origin.

\begin{tabular}{llll}
\hline Code & Isolate & Sources & Country of origin \\
\hline DLCO-AA5 & Beauveria & Grasshopper & Ethiopia \\
DLCO-AA14 & Beauveria & Grasshopper & Ethiopia \\
IITA 18 & Beauveria & Coleoptera & Ethiopia \\
IMI 330189 & M. anisopilae var. acridum & Grasshopper & Niger \\
DLCO-AA83 & Metarhizium & Grasshopper & Ethiopia \\
DLCO-AA109 & Metarhizium & Soil & Ethiopia \\
\hline
\end{tabular}

DLCO: Desert Locust Organization for Eastern Africa; IITA: International Institute of Tropical Agriculture; IMI: International Mycological Institute. 
Effects on emergence of adults from fungal treated last instar LWM larvae

Sixth instar larvae of lesser wax moth were treated with six fungal isolates at different concentrations. The impact of infection on emergence of adults from treated larvae which went through pupation was compared with those untreated control.

\section{Treatment of lesser wax moths and honeybees}

Treatment of lesser wax moths

Six adult LWMs were introduced into a transparent white plastic box $(19 \times 15 \times 10 \mathrm{~cm}$ in length, width and height) lined with wire mesh $(1.5 \times 2$ $\mathrm{cm})$. The box was covered with nylon mesh and held in position by a rubber band. Adults were inoculated by spraying $2 \mathrm{ml}$ of each conidial suspension ranging from $2 \times 10^{4}-2 \times 10^{7}$ conidia $/ \mathrm{ml}$ in three replicates and each experiment was repeated three times (Adane Kasa et al., 1998). Treated insects were provided with sugar solution $(10 \%)$ soaked in cotton wool balls, which were changed at $24 \mathrm{hr}$ intervals and kept in a room temperature set at $25 \pm 2^{\circ} \mathrm{C}$. Similarly, $6^{\text {th }}$ larval instars were inoculated prior to entering into pupation and the effect of the pathogens (isolates) on emergence to adults following treatments was examined. Six last stages $\left(6^{\text {th }}\right.$ larval instars) were used for each isolate and concentration. The experiments had three replicates and were repeated three times.

\section{Treatment of honeybees}

The honeybee (Apis mellifera bandasii) colonies (as non-target insects) were treated with six fungal isolates including IMI 330189, DLCO-AA83, DLCO-AA 109, DLCO-AA5, DLCO-AA14 and IITA 18 in order to investigate the possible impact of the pathogens (isolates) on the non-target beneficial honeybee colonies. Post-treatment mortality of adult locusts was for instance recorded at $24 \mathrm{hrs}$ interval for a period of 14 days (Emiru Seyoum and Merid Negash, 2007).

\section{Confirmation of mycosis}

Following death, each dead bee was removed immediately, surface sterilized with $70 \%$ ethanol for $3 \mathrm{sec}$ (Prior et al., 1992) and kept in Petridishes with moisten tissue papers laid in and incubated under high relative humidity $(>90 \%)$ at temperature set at $25 \pm 2^{\circ} \mathrm{C}$ for 7 days. Comparison of pathogencity of isolates was based on speed of kill. Mortality was considered to be due to mycosis only when external growth of mycelia (external sporulation) following incubation of dead insects was apparent.

All mortality data were corrected using Abbots (1925) formula and cumulative percentage mortality data were subjected to one-way ANOVA using SPSS computer program. Student Newman Keul's Test (SNK) at 5\% levels of significance was used to separate the means.

\section{RESULTS}

In the present study, adult lesser wax moths were found to be susceptible to all fungal isolates used independent of level of conidial concentration which ranged from $2 \times 10^{4}$ to $2 \times 10^{7}$ conidia/ml (Tables 2-6).

\section{Effect of the standard isolate, IMI 330189 and the local isolate IITA 18}

Mortality percentage of LWM due to mycosis in targets infected with isolate IITA 18 increased reaching $88.33 \%$ with the highest conidial concentration $\left(2 \times 10^{7}\right.$ conidia/ml) (Table 2$)$ by day 8 post-treatment. The results showed a significant difference in percent mortality by day 7 post-treatment. This variation in percent mortality based on dose was not however observed by day 8 after treatment (Table 2).

Table 2. Mean percent mortality of lesser wax moth adults treated with isolate IITA 18 at different concentrations over time (days).

\begin{tabular}{|c|c|c|c|c|c|c|c|}
\hline \multicolumn{8}{|c|}{ Percent mortality of day after treatment (Mean \pm S.E) } \\
\hline Conidia/ml & $2(\mathrm{NS})$ & 3 & 4 & 5 & 6 & 7 & 8 \\
\hline $2 \times 10^{4}$ & $7.73 \pm 5.21$ & $29.90 \pm 5.01 \mathrm{ab}$ & $52.22 \pm 4.00 \mathrm{a}$ & $66.67 \pm 2.38 \mathrm{a}$ & $80.23 \pm 5.49 a$ & $91.84 \pm 0.47 a$ & $88.33 \pm 2.55 a$ \\
\hline $2 \times 10^{5}$ & $3.81 \pm 1.91$ & $35.27 \pm 2.95 a$ & $42.56 \pm 3.82 a$ & $53.02 \pm 4.97 \mathrm{a}$ & $56.86 \pm 7.75 b$ & $75.89 \pm 5.01 \mathrm{~b}$ & $85.00 \pm 3.47 \mathrm{a}$ \\
\hline $2 \times 10^{6}$ & $3.81 \pm 1.91$ & $27.18 \pm 6.22 \mathrm{ab}$ & $40.00 \pm 4.97 a$ & $51.1 \pm 7.26 \mathrm{a}$ & $71.51 \pm 3.76 \mathrm{ab}$ & $78.92 \pm 4.97 \mathrm{~b}$ & $88.08 \pm 2.39 a$ \\
\hline $2 \times 10^{7}$ & $1.96 \pm 1.96$ & $15.48 \pm 5.02 b c$ & $31.81 \pm 5.99 \mathrm{ab}$ & $46.35 \pm 3.49 a$ & $61.41 \pm 7.75 \mathrm{ab}$ & $72.86 \pm 6.63 b$ & $88.33 \pm 7.2 \mathrm{a}$ \\
\hline Control & $1.85 \pm 1.85$ & $5.56 \pm 3.21 \mathrm{c}$ & $12.96 \pm 1.85 \mathrm{~b}$ & $20.37 \pm 1.85 b$ & $22.22 \pm 3.21 \mathrm{c}$ & $29.63 \pm 4.90 \mathrm{c}$ & $37.04 \pm 3.7 \mathrm{~b}$ \\
\hline
\end{tabular}

Means within a column followed by the same letter are not significantly different at $\mathrm{p}<0.05$ [Student Newman Keul's (SNK) test at $5 \%$ levels of significance]. NS: Not significant. 
Mycosis in experimental LWM treated with IMI 330189 grew steadily and constantly from day 3 post-treatment and mortality reached $95.83 \%$ at $2 \times 10^{7}$ conidia/ml by day 8 (Table 3 ).

\section{Effects of local isolates}

Percent mortality due to mycosis by the local isolates increased from day two post-application and reached up to $97.43 \%$ (Table 4) adult mortality by day 8 post inoculation. This was apparent for the results on target mortality showed significant differences between the fungal treated and those in the control group (Tables 4, 5, 6 and 7). No significant difference in mortality due to variation in doses (conidial concentration) was, however, recorded. This may indicate that even the lowest concentration $\left(2 \times 10^{4}\right.$ conidia/ml) had caused infection sufficient to cause as much target death as the highest conidial concentration used $\left(2 \times 10^{7}\right.$ conidia/ml $)$ (Tables 4, 5,6 and 7).

Results in the present study revealed that even the lowest conidial concentration $\left(2 \times 10^{4}\right.$ conidia/ml) of almost all isolates tested had resulted in significant level of target lesser wax moth post-treatment mortality as indicated in Table 2. In the course of post inoculation examination, only one individual honeybee was found infected with the IITA 18 (Beauveria spp) and 2 individual honeybees with DLCO-AA83 (Metarhizium spp). No honeybee was found infected with IMI 330189 and with the remaining isolates used (DLCO-AA 109, DLCO-AA5, DLCOAA14).

Table 3. Mean percent mortality of lesser wax moth adults treated with isolate IMI 330189 at different concentrations over time (days).

\begin{tabular}{lcrrrrrr}
\hline \multicolumn{7}{c}{ Percent mortality of day after treatment (Mean \pm S.E) } \\
\hline Conidia/ml & $2(\mathrm{NS})$ & 3 & $4(\mathrm{NS})$ & \multicolumn{1}{c}{5} & \multicolumn{1}{c}{6} & \multicolumn{1}{c}{7} & 8 \\
\hline $2 \times 10^{4}$ & $3.70 \pm 1.85$ & $23.28 \pm 2.60 \mathrm{a}$ & $32.64 \pm 3.91$ & $44.29 \pm 2.97 \mathrm{ab}$ & $51.87 \pm 1.85 \mathrm{ab}$ & $59.88 \pm 1.55 \mathrm{bc}$ & $67.05 \pm 3.99 \mathrm{~b}$ \\
$2 \times 10^{5}$ & $1.85 \pm 1.85$ & $12.92 \pm 3.49 \mathrm{~b}$ & $21.93 \pm 3.81$ & $52.38 \pm 2.38 \mathrm{ab}$ & $54.81 \pm 2.89 \mathrm{ab}$ & $64.85 \pm 7.74 \mathrm{bc}$ & $85.00 \pm 0.00 \mathrm{a}$ \\
$2 \times 10^{6}$ & $3.70 \pm 3.70$ & $32.64 \pm 3.70 \mathrm{a}$ & $36.87 \pm 6.79$ & $58.97 \pm 11.14 \mathrm{a}$ & $67.89 \pm 6.79 \mathrm{a}$ & $80.58 \pm 10.02 \mathrm{ab}$ & $91.66 \pm 8.33 \mathrm{a}$ \\
$2 \times 10^{7}$ & $5.56 \pm 5.56$ & $12.22 \pm 4.90 \mathrm{~b}$ & $21.14 \pm 3.71$ & $50.00 \pm 4.12 \mathrm{~b}$ & $61.48 \pm 4.55 \mathrm{ab}$ & $88.33 \pm 7.26 \mathrm{a}$ & $95.83 \pm 4.17 \mathrm{a}$ \\
control & $0.00 \pm 0.00$ & $14.81 \pm 1.83 \mathrm{c}$ & $31.48 \pm 4.90$ & $33.33 \pm 3.21 \mathrm{c}$ & $42.59 \pm 0.85 \mathrm{~b}$ & $50.00 \pm 3.21 \mathrm{c}$ & $55.56 \pm 0.00 \mathrm{~b}$ \\
\hline
\end{tabular}

Means within a column followed by the same letter are not significantly different at $p<0.05$ (SNK test at $5 \%$ levels of significance).

Table 4. Mean percent mortality of lesser wax moth adults treated with isolate DLCO-AA-5 at different concentrations over time (days).

\begin{tabular}{lrrrrrrc}
\hline \multicolumn{7}{c}{ Percent mortality of day after treatment (Mean \pm S.E) } \\
\hline Conidia/ml & \multicolumn{1}{c}{2} & \multicolumn{1}{c}{3} & \multicolumn{1}{c}{4} & \multicolumn{1}{c}{5} & 6 & \multicolumn{1}{c}{7} & 8 \\
\hline $2 \times 10^{4}$ & $12.96 \pm 1.85 \mathrm{ab}$ & $47.28 \pm 7.01 \mathrm{a}$ & $62.05 \pm 4.46 \mathrm{a}$ & $72.94 \pm 6.69 \mathrm{a}$ & $84.72 \pm 9.72 \mathrm{a}$ & $94.84 \pm 2.60 \mathrm{a}$ & $97.43 \pm 2.56 \mathrm{a}$ \\
$2 \times 10^{5}$ & $14.82 \pm 7.41 \mathrm{ab}$ & $43.57 \pm 5.68 \mathrm{a}$ & $52.35 \pm 3.92 \mathrm{a}$ & $71.24 \pm 2.85 \mathrm{a}$ & $83.28 \pm 2.21 \mathrm{a}$ & $87.06 \pm 6.00 \mathrm{a}$ & $90.91 \pm 9.09 \mathrm{a}$ \\
$2 \times 10^{6}$ & $16.67 \pm 5.56 \mathrm{a}$ & $43.63 \pm 8.97 \mathrm{a}$ & $54.05 \pm 2.57 \mathrm{a}$ & $73.46 \pm 1.70 \mathrm{a}$ & $87.47 \pm 0.45 \mathrm{a}$ & $92.62 \pm 0.496 \mathrm{a}$ & $94.59 \pm 2.76 \mathrm{a}$ \\
$2 \times 10^{7}$ & $18.52 \pm 1.85 \mathrm{a}$ & $43.63 \pm 1.09 \mathrm{a}$ & $61.68 \pm 4.99 \mathrm{a}$ & $79.35 \pm 4.54 \mathrm{a}$ & $93.61 \pm 3.61 \mathrm{a}$ & $94.84 \pm 2.60 \mathrm{a}$ & $94.59 \pm 2.83 \mathrm{a}$ \\
Control & $0.00 \pm 0.00$ & $1.85 \pm 3.21 \mathrm{~b}$ & $7.41 \pm 4.90 \mathrm{~b}$ & $9.26 \pm 3.70 \mathrm{~b}$ & $11.11 \pm 3.21 \mathrm{~b}$ & $24.07 \pm 4.90 \mathrm{~b}$ & $29.63 \pm 4.90 \mathrm{~b}$ \\
\hline
\end{tabular}

Means within a column followed by the same letter are not significantly different at $\mathrm{p}<0.05$ (SNK test at $5 \%$ levels of significance).

Table 5. Mean percent mortality of lesser wax moth adults treated with isolate DLCO-AA-14 at different concentrations over time (days).

\begin{tabular}{lrrrrrrr}
\hline \multicolumn{7}{c}{ Percent mortality of day after treatment (Mean \pm S.E) } \\
\hline Conidia/ml & \multicolumn{1}{c}{2} & \multicolumn{1}{c}{3} & \multicolumn{1}{c}{4} & \multicolumn{1}{c}{5} & \multicolumn{1}{c}{6} & \multicolumn{1}{c}{7} & 8 \\
\hline $2 \times 10^{4}$ & $14.81 \pm 1.85 \mathrm{~b}$ & $26.85 \pm 3.34 \mathrm{ab}$ & $52.59 \pm 4.36 \mathrm{a}$ & $53.05 \pm 4.82 \mathrm{~b}$ & $67.63 \pm 6.73 \mathrm{a}$ & $79.29 \pm 3.31 \mathrm{~b}$ & $78.52 \pm 0.00 \mathrm{~b}$ \\
$2 \times 10^{5}$ & $24.07 \pm 3.70 \mathrm{a}$ & $44.21 \pm 9.62 \mathrm{a}$ & $62.96 \pm 3.70 \mathrm{a}$ & $73.87 \pm 9.82 \mathrm{a}$ & $82.42 \pm 11.22 ?$ & $88.64 \pm 4.90 \mathrm{ab}$ & $96.30 \pm 1.85 \mathrm{a}$ \\
$2 \times 10^{6}$ & $12.96 \pm 3.70 \mathrm{~b}$ & $32.41 \pm 10.94 \mathrm{ab}$ & $60.00 \pm 6.67 \mathrm{a}$ & $68.81 \pm 4.52 \mathrm{ab}$ & $86.90 \pm 5.024 \mathrm{a}$ & $96.97 \pm 3.03 \mathrm{a}$ & $96.30 \pm 1.85 \mathrm{a}$ \\
$2 \times 10^{7}$ & $12.96 \pm 1.85 \mathrm{~b}$ & $34.26 \pm 5.63 \mathrm{~b}$ & $54.44 \pm 4.20 \mathrm{a}$ & $71.03 \pm 2.41 \mathrm{a}$ & $86.90 \pm 5.024 \mathrm{a}$ & $94.20 \pm 2.91 \mathrm{a}$ & $96.30 \pm 1.85 \mathrm{a}$ \\
control & $0.00 \pm 0.00 \mathrm{c}$ & $3.70 \pm 3.70 \mathrm{~b}$ & $5.56 \pm 5.56 \mathrm{~b}$ & $16.67 \pm 3.21 \mathrm{c}$ & $29.63 \pm 4.90 \mathrm{~b}$ & $37.03 \pm 1.85 \mathrm{c}$ & $48.15 \pm 1.85 \mathrm{c}$ \\
\hline
\end{tabular}

Means within a column followed by the same letter are not significantly different at $p<0.05$ (SNK test at $5 \%$ levels of significance). 
Table 6. Mean percent mortality of lesser wax moth adults treated with isolate DLCO-AA-83 at different concentrations over time (days).

\begin{tabular}{lrrrrrrr}
\hline \multicolumn{7}{c}{ Percent mortality of day after treatment (Mean +S.E) } \\
\hline Conidia/ml & \multicolumn{1}{c}{ 2 } & \multicolumn{1}{c}{3} & \multicolumn{1}{c}{4} & \multicolumn{1}{c}{5} & \multicolumn{1}{c}{6} & 7 & \multicolumn{1}{c}{} \\
\hline $2 \times 10^{4}$ & $7.41 \pm 1.85 \mathrm{a}$ & $27.04 \pm 7.04 \mathrm{ab}$ & $46.16 \pm 7.69 \mathrm{ab}$ & $62.18 \pm 3.53 \mathrm{a}$ & $77.68 \pm 5.61 \mathrm{a}$ & $86.11 \pm 7.35 \mathrm{ab}$ & $91.67 \pm 3.70 \mathrm{a}$ \\
$2 \times 10^{5}$ & $1.85 \pm 1.85 \mathrm{~b}$ & $21.44 \pm 2.70 \mathrm{ab}$ & $43.60 \pm 5.13 \mathrm{ab}$ & $57.61 \pm 6.04 \mathrm{a}$ & $79.68 \pm 12.89 \mathrm{ab}$ & $88.89 \pm 11.11 \mathrm{a}$ & $91.67 \pm 3.70 \mathrm{a}$ \\
$2 \times 10^{6}$ & $5.56 \pm 0.00 \mathrm{ab}$ & $29.54 \pm 4.80 \mathrm{a}$ & $46.72 \pm 4.44 \mathrm{ab}$ & $68.63 \pm 1.00 \mathrm{a}$ & $83.74 \pm 6.18 \mathrm{a}$ & $94.44 \pm 5.56 \mathrm{a}$ & $94.44 \pm 1.85 \mathrm{a}$ \\
$2 \times 10^{7}$ & $5.56 \pm 0.00 \mathrm{ab}$ & $25.62 \pm 1.05 \mathrm{ab}$ & $48.72 \pm 6.68 \mathrm{a}$ & $62.52 \pm 3.89 \mathrm{a}$ & $87.44 \pm 8.43 \mathrm{a}$ & $94.44 \pm 5.56 \mathrm{a}$ & $94.44 \pm 1.85 \mathrm{a}$ \\
Control & $0.00 \pm 0.00 \mathrm{c}$ & $12.62 \pm 3.70 \mathrm{~b}$ & $27.78 \pm 0.00 \mathrm{~b}$ & $35.19 \pm 4.90 \mathrm{~b}$ & $50.00 \pm 6.41 \mathrm{~b}$ & $62.96 \pm 3.70 \mathrm{~b}$ & $62.96 \pm 3.70 \mathrm{~b}$ \\
\hline
\end{tabular}

Means within a column followed by the same letter are not significantly different at $\mathrm{p} \leq 0.05$ (SNK test at $5 \%$ levels of significance).

Table 7. Mean percent mortality of lesser wax moth adults treated with isolate DLCO-AA-109 at different concentrations over time.

\begin{tabular}{|c|c|c|c|c|c|c|}
\hline \multirow{2}{*}{ Conidia/ml } & \multicolumn{6}{|c|}{ Percent mortality by day after treatment (Mean+S.E) } \\
\hline & 3 & 4 & 5 & 6 & 7 & 8 \\
\hline $2 \times 10^{4}$ & $30.171 \pm 1.65 \mathrm{ab}$ & $41.92 \pm 6.52 \mathrm{abc}$ & $45.98 \pm 6.04 \mathrm{~b}$ & $65.12 \pm 2.08 b$ & $85.00 \pm 4.90 \mathrm{a}$ & $88.89 \pm 3.21 \mathrm{a}$ \\
\hline $2 \times 10^{5}$ & $22.87 \pm 6.50 \mathrm{bc}$ & $29.15 \pm 6.78 b c$ & $55.46 \pm 10.62 \mathrm{ab}$ & $76.13 \pm 6.95 b$ & $85.99 \pm 1.85 \mathrm{a}$ & $89.56 \pm 0.00 \mathrm{a}$ \\
\hline $2 \times 10^{6}$ & $44.57 \pm 2.29 a$ & $49.27 \pm 5.52 \mathrm{ab}$ & $86.53 \pm 6.83 a$ & $96.97 \pm 3.03 a$ & $100.00 \pm 0.00 \mathrm{a}$ & $100.00 \pm 0.00 \mathrm{a}$ \\
\hline $2 \times 10^{7}$ & $33.37 \pm 4.90 \mathrm{ab}$ & $52.26 \pm 6.92 a$ & $78.95 \pm 7.67 \mathrm{a}$ & $93.27 \pm 3.42 \mathrm{a}$ & $100.00 \pm 0.00 \mathrm{a}$ & $100.00 \pm 0.00 \mathrm{a}$ \\
\hline Control & $12.96 \pm 3.70 \mathrm{c}$ & $25.93 \pm 4.90 \mathrm{c}$ & $37.04 \pm 3.21 b$ & $40.74 \pm 3.21 \mathrm{c}$ & $46.30 \pm 3.21 b$ & $55.56 \pm 5.56 b$ \\
\hline
\end{tabular}

Means within a column followed by the same letter are not significantly different $(\mathrm{P}>0.05)$ (SNK).

In the present series of investigations, adult moths were found to be susceptible to all fungal isolate concentrations ranging from $2 \times 10^{4}$ to $2 \times 10^{7}$ conidia $/ \mathrm{ml}$. Comparison of mortality results among the different fungal isolates applied was, therefore, made at lowest concentration $\left(2 \times 10^{4}\right.$ conidia/ml $)$ of each isolate. Percentage mortality of the lesser wax moth adults due to the applied fungal isolates ranged from approximately $3.7 \%$ on day 2 after treatment with isolate IMI 330189 at $2 \times 10^{4}$ conidia/ml conidial concentration (Table 3) to $97.43 \%$ by isolate DLCO-AA5 at $2 \times 10^{7}$ conidia/ml conidial concentration by day 8 post-treatment (Table 4). On day 8, there was no significant difference $(\mathrm{P}>0.05)$ in mortality of the treated adults between isolates DLCO-AA5 (61.26\%), IMI 330189 (67.05\%), DLCO-AA83 (76.77\%), DLCO-AA14 (73.85\%) and DLCO-AA 109 (62.27\%), respectively.

As the number of days progressed, isolates DLCO-AA5, IMI 330189 and DLCO-AA83 caused high mortality, $97.43 \%, 95.83 \%$ and $94.44 \%$, respectively by day 8 after inoculation adults. Isolates DLCO-AA 109, DLCO-AA14, and IITA 18 also showed target mortalities of $96.30 \%, 95.83 \%$ and $78.44 \%$, respectively by day 8 post-applications. In all cases, mortality of adults treated with the different fungal isolates increased gradually posttreatment until $100 \%$ was recorded with isolates DLCO-AA5, IMI 330189, DLCO-AA83 and DLCO-AA
109, respectively. On day 8 isolates DLCO-AA14 and IITA 18 had cumulative percent mortalities of $96.3 \%$ and $88.33 \%$, respectively, at $2 \times 10^{7}$ conidia/ml (Tables 2 and 5).

$6^{\text {th }}$ instar larvae of lesser wax moth which went into pupation following treatment with different fungal isolates at different spore concentration showed no significant difference in emergence into adult (Table 8). Although no available data are available to compare currently on this aspect, it is assumed that the fungal spores were unable to cause infection during the pupation period before they emerged as adults. This could be attributed to the temperature and humidity conditions when the larvae were at encased during pupation.

Mycosed lesser wax moths showed external sporulation characteristics of the respective fungi when surface sterilized as means of confirmation of mycosis (Emiru Seyoum et al., 1994; Emiru Seyoum, 2001; Prior et al., 1992;). Similarly, the post-death examination of Apis mellifera (Ethiopian race) showed that isolate IMI 330189 (Metarhizium spp) had no effect. With isolate IITA 18 (Beauveria spp.) 1 honeybee $(0.5 \%)$ was infected and with isolate DLCO-AA83 (Metarhizium spp), 2 honeybees (1\%) were found infected. The Beauveria infected honeybees produced a green characteristic sporulation when 
the spores were streaked on malt extract agar and incubated at $25^{\circ} \mathrm{C}$ in the dark for 7 days.

Table 8. Percentage emergence of Achroia grisella adults following treatments of $6^{\text {th }}$ instar larvae with six fungal isolates at different concentrations.

\begin{tabular}{|c|c|c|}
\hline Isolate & $\begin{array}{l}\text { Concentration } \\
\text { (conidia/ml) }\end{array}$ & Percent mortality \\
\hline \multirow[t]{5}{*}{ DLCO-A-5 } & $2 \times 10^{4}$ & $97.2 \pm 2.8$ \\
\hline & $2 \times 10^{5}$ & $94.4 \pm 2.8$ \\
\hline & $2 \times 10^{6}$ & $94.4 \pm 2.8$ \\
\hline & $2 \times 10^{7}$ & $100 \pm 0.0$ \\
\hline & Control & $97.2 \pm 2.8$ \\
\hline \multirow{5}{*}{ DLCO-AA-14 } & $2 \times 10^{4}$ & $94.4 \pm 2.8$ \\
\hline & $2 \times 10^{5}$ & $94.4 \pm 2.8$ \\
\hline & $2 \times 10^{6}$ & $94.4 \pm 2.8$ \\
\hline & $2 \times 10^{7}$ & $91.7 \pm 4.8$ \\
\hline & Control & $97.2 \pm 2.8$ \\
\hline \multirow[t]{5}{*}{ IITA-18 } & $2 \times 10^{4}$ & $94.4 \pm 2.8$ \\
\hline & $2 \times 10^{5}$ & $91.7 \pm 4.8$ \\
\hline & $2 \times 10^{6}$ & $97.2 \pm 2.8$ \\
\hline & $2 \times 10^{7}$ & $88.9 \pm 2.8$ \\
\hline & Control & $100.0 \pm 0.0$ \\
\hline \multirow[t]{5}{*}{ IMI 330189} & $2 \times 10^{4}$ & $100.0 \pm 0.0$ \\
\hline & $2 \times 10^{5}$ & $97.22 \pm .8$ \\
\hline & $2 \times 10^{6}$ & $97.2 \pm 2.8$ \\
\hline & $2 \times 10^{7}$ & $94.4 \pm 2.8$ \\
\hline & Control & $100.0 \pm .0$ \\
\hline \multirow[t]{5}{*}{ DLCO-AA-83 } & $2 \times 10^{4}$ & $94.4 \pm 2.8$ \\
\hline & $2 \times 10^{5}$ & $97.2 \pm 2.8$ \\
\hline & $2 \times 10^{6}$ & $94.4 \pm 2.8$ \\
\hline & $2 \times 10^{7}$ & $94.4 \pm 2.8$ \\
\hline & Control & $88.9 \pm 2.8$ \\
\hline \multirow[t]{5}{*}{ DLCO-AA-109 } & $2 \times 10^{4}$ & $100.0 \pm 0.0$ \\
\hline & $2 \times 10^{5}$ & $100.0 \pm 0.0$ \\
\hline & $2 \times 10^{6}$ & $94.4 \pm 2.8$ \\
\hline & $2 \times 10^{7}$ & $94.4 \pm \overline{2.8}$ \\
\hline & Control & $97.2 \pm 2.8$ \\
\hline
\end{tabular}

Means within a column followed by the same letter are not significantly different at $p \leq 0.05$ (SNK test at $5 \%$ levels of significance).

\section{DISCUSSION}

Fungal diseases of insects have been known since 1934 and at present about 700 species of fungi in 700 genera are recognized to cause infection in insects (Goettel, 1992). Nevertheless, relatively few have thus far been developed for pest control. The potential of entomopathogens against the wax moth has not been established yet. In the present work, laboratory based studies have shown that fungal isolates belonging to genera Beauveria and Metarhiziuzm have the potential towards the management of wax moths. The results in the present work are in agreement with a previous similar work on greater wax moth (Namusana and Emiru
Seyoum, 2010). The standard isolate, IMI 330189 (Metarhizium anisopilae var. acridium) and local isolates (note materials and methods and, results sections) were evaluated for their virulence against adult lesser wax moth.

Comparisons of results herein are made based on previous similar works but on different groups of insects. However, it is apparent that it is difficult to reach conclusions as the results, the target insects, the isolates, fungal concentrations, and conditions under which the experiments were conducted were different. As elucidated earlier (Tables 2-6) adult lesser wax moths (LWM) were found to be susceptible to all fungal isolates at different concentrations ranging from $2 \times 10^{4}$ to $2 \times 10^{7}$ conidia/ml. This implies that the subject insect, LWM adults were susceptible to even the lowest dose (concentration). This is probably related to the fact that once the conidia penetrate the insect cuticle; the fungus multiplies inside the host (Burge, 1988). As the consequence, comparison of target mortality results due to mycosis was carried out at the lowest concentration used $\left(2 \times 10^{4}\right.$ conidia $\left./ \mathrm{ml}\right)$ of each isolate used. The findings revealed that infection of over $85 \%$ mortality could be achieved by day 8 posttreatment with most fungal isolates (Table 2-6) except isolate IMI 330189 in which mortality by day 8 with the lowest concentration was $67.05 \%$ (Table 3). This finding is in agreement with previous work in which Metarhizium flavoviride (F1985) was topically applied on Valanga irregularis (Walker) an occasional pest of horticultural crops and $100 \%$ adult mortality was observed with $85 \%$ of the dead insects producing conidia (Milner and Prior, 1994). Adult LWM mortality of $97.43 \%$ (Table 4 ) and $95.83 \%$ (Table 3) were recorded with isolates DLCO-AA5, IMI 330189 and DLCO-AA 109, respectively by day 8 post inoculation. Over $85 \%$ produced conidia when cadavers of infected insects were surface sterilized and incubated. This finding is also in accordance with that recorded on adults of Glossina morsitans morsitans in which tested isolates of Beauveria bassiana and Metarhizium anisopilae were found to be pathogenic against adult tsetse with high mortalities ranging between 60 and $95 \%$ on days 15-18 post infection and $100 \%$ mortalities by week 4 post-treatments using an aqueous spore suspension of $2 \times 10^{7}$ conidia/ml (Kaaya, 1989).

Beneficial insects such as the honeybees are a group of non-target organisms meriting special attention when applying entomopathogens as myco-insecticides. Both Beauveria and $M$. 
anisopilae have wide host ranges and numerous records of infection of other hymenoptera have been reported (Goettel et al., 1990). Ideally, isolates of pathogens used as a myco-insecticide should have a narrow host range, not infecting important groups of beneficial arthropods and should not pose a large risk of creating epizootics in non-target species after release (Burge, 1988). Data obtained from the present laboratory investigations showed that with isolate DLCO-AA83 (Metarhizium spp) 2 honeybees were infected; with isolate IITA 18 (Beauveria spp) 1 individual honeybee was infected while isolate IMI 330189 had no effect. The no-effect results obtained using isolate IMI 330189 (Metarhizium spp) in the present work are in agreement with the finding of Price and Muller (1994) where four viable and reproductive active Apis mellifera scutellata colonies were dusted with dry spores (approximately $5 \times 10^{10}$ conidia $/ \mathrm{ml}$ ) and remained healthy with no trend, such as decline in food or brood reserves 7 months post-application. However, it is in disagreement with Ball et al. (1994) who found less than $1 \%$ infection in honeybees (Apis mellifera, L) after exposure in the laboratory to the Metarhizium isolate IMI 330189. No spore sporulation on the surface sterilized and incubated honeybees cadavers occurred from Metarhizium isolate IMI 330189. This isolates probably had required a longer infection period or the spores were still in the resting phase in the hemocoel. In agreement with the mortality data recorded using isolate DLCO-AA83 in which conidia sporulated when 2 cadavers obtained from a colony treated at a spore concentration of $2 \times 10^{7}$ conidia/ml, limited mortality was also found in the honeybee as the result of infection by isolate IMI 330189 (Ball et al., 1994). Similarly, isolate IITA 18 (Beauveria spp) showed mycelial external growth (sporulation) from only 1 dead honeybee after surface sterilizing cadavers from the treated colony. These findings are in agreement with work by Vandenberg (1990) who demonstrated that strains of Beauveria bassiana caused mycosis among honeybees treated with high doses of conidia, although the results were not pronounced.

Tested native isolates have shown promising results in the present laboratory based experiments. The favourable conditions in the laboratory might have, however, enhanced the performance of the pathogens more than what could be expected in nature where, sub-optimal conditions for the growth and viability, many different antagonists and adverse weather conditions may prevail. Therefore, beneficial insects such as the honeybee should be included in impact monitoring when myco-insecticides are evaluated under large scale operations.

\section{ACKNOWLEDGEMENTS}

The authors are very grateful to Holetta Bee Research Centre administration and staff members for the assistance rendered. We also acknowledge the Desert Locust Control Organization for Eastern Africa (DLCOEA) for allowing their facilities and fungal isolates to use without any restriction. The authors appreciate the contributions by the anonymous reviewers whose comments were useful to get the article in its final shape.

\section{REFERENCES}

1. Abbots, W.S. (1925). A method of comparing the effectiveness of an insecticide. J. Econ. Entomol. 18:265-267.

2. Adane Kasa, Moore, D. and Archer, S.A. (1998). Potential of Beauveria bassiana for the control of maize weevil and bean in the laboratory. Pest Mgt. J. Eth. 2:56-65.

3. Ali, A.D., Barky, N.M., Abdelatif, M.A. and EJSawaf, S.K. (1973). The control of greater wax moth, Galleria mellonella L. by chemicals, I.Z. Angew. Entomol. 74:170-177.

4. Amsalu Bezabih, Nuru Adugna, Sarah, E., Radloffb, H. and Randall, H. (2004). Multivariate morphometric analysis of honeybees (Apis mellifera) in the Ethiopian region. Apidologie 35:71-81.

5. Ball, B.V., Pye, B.J., Carreck, N.L., Moore, D. and Batman, R.P. (1994). Laboratory testing of a mycopesticide on non-target organisms. The effect of an oil formulation of Metarhizium flavoviride applied to Apis mellifera. Biocontrol Sci. and Tech. 4:289-296.

6. Burges, H.D. (1978). Control of wax moth: Physical and biological methods. Bee World 59:129-138.

7. Burge, M.N. (1988). Fungi in Biological Control Systems. Manchester University Press.

8. Cantwell, G.E. and Smith, L.J. (1970). Control of the greater wax moth Galleria mellonella in honeycomb and comb honey. Am. Bee J. 10:141-143.

9. Desalegn Begna (2001). Honeybee pest and predators of Ethiopia. $3^{\text {rd }}$ Proceedings of National Conference of Ethiopian Beekeeping Association, pp. 59-67. Addis Ababa, Ethiopia.

10. Desalegn Begna and Amsalu Bezabeh (2001). Survey of honeybee pest and pathogen in south and south-west parts of Ethiopia. 16 
Proceedings of Ethiopian Veterinary Association, pp. 86-93.

11. Donald, J.B., Charles, A.T. and Norman, F.J. (1989). An Introduction to the Study of Insects. Harcourt Brace College Publishers, San Diegi, USA.

12. Emiru Seyoum, Moore, D. and Charnley, A.K. (1994). Reduction in flight activity and feeding ability of the desert locust, Schistocerca gregaria after infection by Metarhizium flavoviride. J. of Applied Entomol. 118:309-315.

13. Emiru Seyoum (2001). The synergistic effects of Metarhizium anisopliae (Sorokin) with the acyl urea insecticides Teflubenzuron and Diflubenzuron against the desert locust, Schistocerca gregaria (Orthoptera: Acrididae). SINET: Ethiop. J. Sci. 24(1):113-125.

14. Emiru Seyoum and Merid Negash (2007). Studies on the field performance of Metarhizium anisopliae var. acridum (Green Muscle $^{\circledR}$ ) against mixed populations of grasshopper in Ethiopia. SINET: Ethiop. J. Sci. 30(1):55-64.

15. Floyd, E. and Paul, H. (1976). Life cycle of Ascosphaera apis. American bee Journal $\mathbf{1 1 6}$ (10):484.

16. Goettel, M.S. (1992). Fungal agents for biocontrol. In: Biological Control of Locusts and Grasshoppers, PP. 123-131, (Lomer, C.J. and Prior, C., eds). CAB International, UK.

17. Goettel, M.S., Poprawski, T.J., Vanderberg, J.D., Li, Z. and Roberts, D.W. (1990). Safety microbial insecticides. In: Safety to Non-Target Invertebrates of Fungal Biocontrol Agents, PP. 209-232, (Laird, M., Lacey, L.A. and Davidson, E.W., eds). CRC Press, Boca raton.

18. Good, M.E., Morrison, F.O. and Mankiewiicz, N.E. (1953). Lipodolytic enzymes extracted from Galleria mellonella L. (Lepidoptera: Pyralidae) reared on natural and artificial media. Can. Ent. 85:252-253.

19. Hall, R.A. (1976). A bioassay of pathogenicity of Verticillium lecanii conidiospores on the aphid, Macrosiphoniella sanborni. J. Invertbr. Pathol. 27:41-48.
20. Haydak, G.H. (1976). Is wax a necessary constitute of the diet of wax moth larvae? Ann. Ent. Soc. America 29:41-48.

21. Kaaya, G. P. (1989). Glossina morsitans morsitans: Mortalities caused in adults by experimental infection with entomopathogenic fungi. Acta Tropica. 46:107-114.

22. MAAREC (2000). Mid-Atlantic Apicultural Research \& Extension Consortium (MAAREC) publication 4.5. Original from American Bee J. web site: http// AREC. Cas.psu.edu.

23. Mike, P., Griffiths, C. and Weaving, A. (2002). Field Guide to Insects of South Africa. Hirt and Carter Cape (Pty) Ltd., South Africa.

24. Milner, R.J. and Prior, C. (1994). Susceptibility of the Australian plague locust, Chortoicetes terminifera and the wingless grasshopper, Phaulacridium vittatum, to fungus Metarhizium spp. Biological Control 4:132-137.

25. Namusana, H. and Emiru Seyoum, (2010). Evaluation of native fungal isolates and Metarhizium anisopliae var. acriidum against adult greater wax moth, Galleria mellonella (L) (Pyralidae: Lepidoptera) in Ethiopia. SINET: Eth. J. Sci. Accepted.

26. Price, R.E. and Muller, E.J. (1994). Use of pathogens as possible bio-control agents of locusts. PPRI progress report 05:9/94. Contract Research No. LR/7 for Directorate of Natural Agricultural Resource Conservation, Department of Agriculture.

27. Prior, C., Lomer, C.J., Herren, H., Paraiso, A., Kooyman, C. and Smith, J.J. (1992). The IIBC/IITA/DFPV Collaborative Research Program on the biological control of locusts and grasshoppers. In: Biological Control of Locusts and Grasshoppers, PP. 8-18, (Lomer, C. J. and Prior, C., eds). CAB International, UK.

28. Seneshaw Aysheshim, Emiru Seyoum and Dawit Abate (2003). Evaluation of Ethiopian Isolates of Entomopathogenic Fungi as Potential Biological Control Agents of the Desert Locust, Schistocerca gregaria. Pest Management Journal of Ethiopia 7:1-9.

29. Vandenberg, J.D. (1990). Safety of four entomopathogens for caged adult honeybees: (Hymenoptera: Apidae). J. Econ. Enomol. 83:756-759. 